\title{
Örgüt Kültürü Analizi: Üniversite Stratejik Planlarına Yönelik Bir Araştırma (Organizational Culture Analysis: A Research on University Strategic Plans)
}

\section{Emel BAHAR}

a Tarsus Üniversitesi, Meslek Yüksekokulu, Tarsus, Mersin, Türkiye. ebahar@tarsus.edu.tr

\begin{tabular}{ll}
\hline MAKALE BİLGISI & ÖZET \\
\hline Anahtar Kelimeler: & Amaç - Bu araştırmada, yapı, misyon, girdiler, kaynaklar, paydaşlar ve çevreyle ilişkileri \\
Örgüt kültürü & açısından karmaşı örgütler olarak nitelendirilebilen üniversitelerin, stratejik plan gereği \\
Stratejik plan & yapmak durumunda oldukları -ancak tanımı, sınırları, bileşenleri, analiz yöntemleri itibariyle \\
Devlet üniversitlilik ve karmaşa içeren- örgüt kültürü ölçümlerini, hangi alt boyutlarda ve yöntemlerle & yaptıklarını, mevcut stratejik planlarını inceleyerek ortaya koymak amaçlanmıştır.
\end{tabular}

Gönderilme Tarihi 24 Nisan 2020

Revizyon Tarihi 15 Haziran 2020

Kabul Tarihi 20 Haziran 2020

Makale Kategorisi:

Araştırma Makalesi

Yöntem - Araştırmanın çalışma grubunu 128 devlet üniversitesi oluşturmaktadır. Araştırma tarama modelinde desenlenmiş olup, veriler üniversitelerin stratejik planlarında yer alan örgüt kültürü analizlerini -var olduğu şekliyle- betimlemeye çalışmak için doküman inceleme tekniği kullanılmıştır.

Bulgular - Araştırma sürecinde aktif stratejik plana sahip üniversitelerin sadece \%17'si örgüt kültürü analizlerini “Üniversiteler için Stratejik Planlama Rehberi"nde önerilen yöntemlerle yapmış, diğerleri (\%83) herhangi bir ölçüm yapmadan sadece genel değerlendirme ifadelerine yer vermişlerdir. 128 Devlet üniversitesinin 34'üu, (\%33) stratejik planlarında örgüt kültürlerine ilişkin bilgiye yer vermemişlerdir.

Tartışma - Üniversitelerin stratejik planlarında, örgüt kültürü analizlerinin amacına uygun yapılma oranı çok düşük düzeyde kalmıştır. Ölçümlenmeyen göstergeler, karşılaştırmalı analiz yapmaya fırsat veremeyeceğinden, hazırlanan planların örgütler üzerindeki etkisini izlemek de mümkün olamayacaktır. Stratejik planların bir zorunluluk ve prosedür olarak görülmesi, stratejik planlamanın gereği gibi uygulanması sonucu elde edilecek kazanımlar konusunda yeterli bilgiye sahip olunmaması, gerçekçi bir yaklaşım ve özenle uygulanmaması gibi konular bu sonucun nedenleri olarak sayılabilir.

\begin{tabular}{|c|c|}
\hline ARTICLE INFO & ABSTRACT \\
\hline $\begin{array}{l}\text { Keywords: } \\
\text { Organization culture } \\
\text { Strategic plan }\end{array}$ & $\begin{array}{l}\text { Purpose -With this study, the organizational culture measurements of universities, which can } \\
\text { be defined as complex organizations in terms of structure, mission, inputs, resources, } \\
\text { stakeholders and their relations with the environment, it is aimed to reveal what they did with } \\
\text { which dimensions and methods by examining their existing strategic plans. }\end{array}$ \\
\hline Received 24 April 2020 & $\begin{array}{l}\text { Design/methodology/approach - The study group of the research consists of } 128 \text { public } \\
\text { universities. The research was designed in the document screening model and the document } \\
\text { analysis technique was used to try to describe the organizational culture analyzes- as they exist- } \\
\text { in the strategic plans of the universities. }\end{array}$ \\
\hline $\begin{array}{l}\text { Revised } 15 \text { June } 2020 \\
\text { Accepted } 20 \text { June } 2020\end{array}$ & $\begin{array}{l}\text { Findings -In the research process, only } 17 \% \text { of the universities with an active strategic plan } \\
\text { made their organizational culture analyzes using the methods proposed in the "Strategic } \\
\text { Planning Guide for Universities", while others (83\%) included only general evaluation } \\
\text { statements without making any measurements. } 34 \text { of the } 128 \text { state universities }(33 \%) \text { did not } \\
\text { include information about organizational cultures in their strategic plans. }\end{array}$ \\
\hline $\begin{array}{l}\text { Article Classification: } \\
\text { Research Article }\end{array}$ & $\begin{array}{l}\text { Discussion - In the strategic plans of universities, the rate of performing the organizational } \\
\text { culture analysis in accordance with its purpose remained at a very low level. It will not be } \\
\text { possible to monitor the impact of the prepared plans on the organizations, as the indicators that } \\
\text { are not measured cannot provide an opportunity for comparative analysis. Topics such as the } \\
\text { fact that strategic plans are considered as a necessity and procedure, not having enough } \\
\text { information about the gains to be obtained as a result of the proper implementation of strategic } \\
\text { planning, a unrealistic approach and uncareful implementation can be counted as the reasons } \\
\text { for this result. }\end{array}$ \\
\hline
\end{tabular}




\section{Giriş}

Dinamik iş dünyasında örgütler, özellikle 20. Yüzyılın son çeyreğinden buyana, büyüme-gelişme, kârlarını maksimize edebilme, devamlılıklarını sağlayabilme, farklılaşma, rekabet üstünlüğü elde edebilme, kısaca kalıcı başarıya ulaşabilmek için değişik yöntemler bulmaya çabalamışlardır. Bunu sağlayabilecek en önemli unsurların, fiziksel aktiflerinden çok, örgütlerin sahip oldukları maddi olmayan, bilgi tabanlı, entelektüel varlıklarıyla formüle edilen değerler oldukları fark edilmiştir. Bu arada sosyoloji, psikoloji, antropoloji ve etnoloji literatüründe yer alan kültür kavramı da örgütsel yönetim yazınına giriş yapmış, giderek önemi artmaya ve örgütlerin yapısal sermayeleri kapsamında değerlendirilmeye başlanmıştır. En genel tanımla kültür, insanoğlunun yaşadığı, öğrendiği, nesiller boyu aktardığı soyut ve somut değerler topluluğudur. Değerler, inançlar, normlar, semboller, iletişimde kullanılan dil, sözsüz iletişim tarzı, alışkanlıklar, ahlaki yaklaşımlar, kullanılan teknoloji, üretilen sanat, hikayeler, törenler vb. unsurları örnek olarak sayabiliriz. Buradan hareketle örgüt kültürünü, örgütteki tüm paydaşların paylaştığı, değerler, inançlar, anlayış ve kurallar topluluğu şeklinde tanımlayabiliriz.

Her örgütün kültürünün kendine özgü olması, örgütteki hemen her şey ile ilişkilendirilebilmesi, örgüt kültürünün sınırlarının belirlenmesi, tanımlanması, özelliklerinin ortaya konması, sınıflandırılması, ölçümlenmesi gibi konuları çeşitlendirmekte ve karmaşık kılmaktadır. Örgüt kültürü konusunda yapılan çalışmaları sınıflamaya tabi tutarsak, örgüt kültürünü kategorize etmeye, tipolojiler oluşturmaya yönelik araştırmalar ve örgütlerin kültürel dokusunu ortaya çıkarmaya dönük araştırmalar şeklinde ikiye ayrıldığını görebiliriz (Danışman ve Özgen, 2003:94). Alan yazını incelediğimizde, örgüt kültürü analizinde nitel yöntem mi, nicel yöntem mi ya da her iki yöntemin mi kullanılacağı tartışma konusudur. Yöntemlerde olduğu gibi, analizde temel alınacak kültür ögeleri, boyutları, değişkenleri ve sınırları konusunda da tam bir görüş birliği sağlanamadığı görülmektedir.

Örgüt kültürünün kurumların başarıları üzerinde kritik bir rolü olduğu bir gerçektir. Ancak yukarıda açıklandığı gibi, tanımı, sınırları, bileşenleri, analiz yöntemleri itibariyle çeşitlilik ve karmaşa içeren örgüt kültürü konusunda; yine karmaşık yapıya sahip üniversitelerin yaklaşım ve uygulamalarının ne olduğunun belirlenmesi düşüncesi bu çalışmanın çıkış noktasını oluşturmuştur. Bunun için ülkemizde kamu yönetiminde 2006 yılından itibaren uygulanmakta olan stratejik planlama uygulaması gereği hazırlanan üniversite stratejik planlarının, özdeğerlendirme bölümündeki örgüt kültürü analizleri incelenerek betimlenmeye çalışılmıştır.

\section{Kavramsal Çerçeve}

\section{Stratejik Planlama}

Stratejik plan, örgütün geneli hakkında bilgi sağlamak için sistematik bir süreç ortaya koyar; örgütün çevresini keşfetmesi, güçlü ve zayıf yanlarını analiz etmesi, misyon ve hedeflerini belirlemesi, paydaşlarını tanımlaması ve eylem planlarını uygulaması için çerçeve oluşturur (Poister ve Streib, 2005: 46; Blair, 2004: 102-103). Bryson'a göre (1988:11) stratejik planlama, bir örgütün ne olduğuna, neyi, niçin yaptığını şekillendiren ve yönlendiren temel karar ve eylemleri üreten disiplinli bir çabadır; temelde yönetici, lider ve planlamacılara stratejik düşünme ve hareket etmeye yardımcı olmak için düzenlenmiş işlemler araçlar ve kavramlar grubudur; örgütün gelişmesine ve etkili stratejinin yerleşmesine de katkı sağlamaktadır. Diğer bir ifadeyle stratejik planlama, mevcut kaynakları etkili ve verimli biçimde kullanarak örgütün gelecekte varmak istediği noktaya ulaşmak amacıyla yürüttüğü planlı faaliyetlerdir. Bu anlamda, mevcut durumun tespiti, bulunulan noktaya nasıl gelindiği, nereye doğru gidilmek istendiği ve gidilmek istenen noktaya nasıl ulaşılacağı gibi konular stratejik planlamanın temelini oluşturur. Stratejik yönetimi de kısaca "bir örgütün hedeflerine ulaşmasını mümkün kılan fonksiyonel kararların formülasyonu, yürütülmesi ve değerlendirilmesidir" şeklinde tanımlayabiliriz (Bryson, 2012: 105-143; Albrechts, 2001: 295; Toma,2010).

Stratejik planlama günümüz örgütlerince yaygın olarak kullanılan bir yönetim aracıdır ve diğer planlama süreçleri gibi, stratejik planlamanın da kendine özgü yönleri vardır. Bryson'a göre (2012: 11) stratejik planın alfabesi şu üç soruya cevap vermektir. Neredeyiz?, Nerede olmak istiyoruz?, Bu noktaya nasıl ulaşabiliriz? Stratejik planlama ile örgüt-çevre ilişkisi bütün olarak görülür; iç ve dış çevre analizleriyle aralarındaki etkileşim incelenerek hareket noktaları belirlenir ve örgüt amaçları gerçekleştirilmeye çalışılır. Bununla birlikte; stratejik planlama bir örgütte görev alan her düzeydeki çalışanın katılımını ve kurum yöneticisinin tam desteğini içeren -sonuç almaya yönelik- çabaların bütününden oluşur. Ayrıca, stratejik planlamanın 
kurumlar için genel amacl, kurum içerisinde durum analizleri yaparak kurumun zayıf yönlerini tespit etmek ve bu zayıf yönlerini geliştirip güçlendirerek kurumun kendi faaliyet alanında söz sahibi konuma gelmesini sağlamaktır. Bu noktadan hareketle stratejik planlamanın iki temel amaç üzerine yapılandığı söylenebilir. Bunlardan birincisi farklılıkların tespiti ile yeni ve farklı fikirleri ortaya koyarak kurumun uzun dönemde büyümesini sağlamak ve bu büyümenin rekabet avantajını ele geçirmek. Diğeri ise, kurumu daha etkin ve verimli bir kurum kimliğine kavuşturabilmektir (Yükselen, 1998:29).

\section{Kamu Yönetiminde ve Üniversitelerde Stratejik Planlama}

Kamu kesimi, hızla değişimin ve reformların yaşandığı 1980'li yıllarda değişimlere adapte olabilmek, toplumun beklentilerini karşılayabilmek, kaynaklarını rasyonel kullanabilmek açısından geleneksel kamu yönetimi yaklaşımını terk ederek, yeni kamu yönetimi adı verilen bir paradigmayı benimsemişlerdir. Bu yeni yaklaşım içerisinde özel kesimce kullanılan planlama ve karar alma enstürmanları kullanılmaya ve kamu idarelerindeki atalete ve verimsizliğe çözüm üretmek adına stratejik planlamalar yapılmaya başlanmıştır.

$\mathrm{Bu}$ yeni anlayıs, politika yerine yönetime, performansa ve verimliliğe odaklanan, kamu idarelerindeki bürokrasiye karşı olan, rekabeti teşvik ederek ve piyasa temelli olan, maliyetleri azaltan, yöneticilere esneklik tanıyan, hedeflere odaklı bir yönetim anlayışını içeren özelliklere sahiptir (Bevir vd., 2003:1). Çünkü kamu örgütlerinin sahip olduğu çeşitli finansal, fiziksel ve beşeri kaynakların tutarlı ve etkin şekilde kullanılması için maksimum düzeyde entegre edilmesi ve koordinasyonun sağlanarak iyi yönetilmesi şarttır. Bu da ancak, stratejik yönetim anlayışına sahip olmakla ve etkin bir stratejik plan oluşturup, uygulamakla sağlanabilmektedir. (Büyük ve Barca, 2011:163)

Stratejik planlama, 1970'li yıllardan sonra yükseköğretimde, 1980'li yıllardan sonra ise diğer düzeylerdeki eğitim kurumlarında kullanılmaya başlanmıştır. Ülkemizde ise 2000'li yıllarda gündeme gelmiş; 2003 yılında 5018 sayılı Kamu Malî Yönetimi ve Kontrol Kanunu TBMM'de kabul edilmiş, 2006 yılında da yürürlüğe girmiştir. 5018 sayılı Kanun, kamu idarelerinin; kalkınma planları, programlar, ilgili mevzuat ve benimsedikleri temel ilkeler çerçevesinde geleceğe ilişkin misyon ve vizyonlarını oluşturmak, stratejik amaçlar ve ölçülebilir hedefler saptamak, performanslarını önceden belirlenmiş olan göstergeler doğrultusunda ölçmek ve bu sürecin izleme ve değerlendirmesini yapmak amacıyla katılımcı yöntemlerle stratejik plan hazırlayacağına hükmetmektedir (T.C.Resmî Gazete, 24.12.2003, 25326, Md: 9). Stratejik planın "Kamu idarelerinin orta ve uzun vadeli amaçlarını, temel ilke ve politikalarını, hedef ve önceliklerini, performans ölçütlerini, bunlara ulaşmak için izlenecek yöntemler ile kaynak dağılımlarını içeren plan" (5018,Md:3/n) şeklinde tanımlandığı ilgili kanun uyarınca; stratejik planlamanın tüm kamu kurumlarında yaygınlaştırılması, -aşamalı bir geçiş planı dâhilinde ilerlemesi- sağlanmıştır. 2006 yılından başlayarak devlet üniversitelerinde de kademeli olarak stratejik planlama zorunlu hale getirilmiştir ve beş yıllık dönemler itibariyle yapılması öngörülmüştür.

Üniversiteler, hizmet ağırlıklı olmaları sebebiyle stratejik yönetim anlayışı çerçevesinde yapacakları stratejik planlarında işletmelerden daha farklı planlama yapmak zorundadırlar. Bu nedenle, üniversitelerde stratejik yönetim anlayışı, eğitim sisteminin etkinliği ve bilimsel gelişmelerin gerekleri doğrultusunda, yükseköğretim sektörünü rekabetçi bir yapıya kavuşturmak hedefi ekseninde şekillenmeli ve yönetim süreçleri ile kaynak kullanımında etkinliğin artırılıp sağlanması ve performansa dayalı bir yönetim anlayışına yönelik değişim ihtiyacını da ortaya koymalıdır. Kısaca, -strateji geliştiren tüm diğer kurumlar gibi üniversiteler de- stratejik planlarında ifade edecekleri konular ve temel değerler üzerinde çok ciddi bir şekilde düşünmelidirler (Birinci, 2014:137; Yılmaz ve Kesik, 2010:156; Collins ve Porras, 1996:66). Diğer taraftan, üniversitelerde gerçekleştirilen stratejik planlama çalışmalarının, sadece ilgili üniversite için değil; üniversitenin sistem düşüncesi gereği etkileşimde bulunduğu tüm kişi, kurum ve kuruluşlar açısından da etki sahibi olduğu bilinci ile gerçekleştirilmesi elzemdir (Özmen vd, 2013:37).

Yükseköğretim kurumlarında oluşturulacak stratejik planlama süreci şu aşamalardan oluşmaktadır: Neredeyiz sorusunun cevaplandığı durum analizi, nereye ulaşmak istiyoruz sorusuna cevap arandığı geleceğe bakış (misyon, vizyon ve temel değerler), farklılaşma stratejisi ve strateji geliştirme, gitmek istediğimiz yere nasıl ulaşırız sorusunun cevaplandığı eylem planları, performans programı ve son olarak başarımızı nasıl takip eder ve değerlendiririz sorusunun cevaplandığ izleme ve değerlendirme, bölümlerinden oluşmaktadır. 
Stratejik planlamaya durum analizi yaparak, örgütün güçlü ve zayıf yönleri ile karşılaşabileceği tehdit ve fırsatları belirlemeye çalışarak temel oluşturmaya çalışılır. Bryson'a göre (2012) dış çevre analizi, politik, ekonomik, sosyal ve teknolojik eğilimler ile değişim, güncel ve potansiyel müşteri ve rakipler ile paydaş grupların yapısı ve statüsü tarafından belirlenir. İç çevre analizinde ise üç değerlendirme önemlidir; örgütün kaynakları (girdiler), süreç ve performans (çıktılar). SWOT analizi tam burada öne çıkmaktadır; çünkü her etkin strateji, örgütün zayıf yanları ile karşı karşıya olduğu tehditlerin üstesinden gelir ve örgütün güçlü yanları ile sahip olduğu fırsatların sunduğu avantajlar ile oluşturulur (Bryson, 2012:76). Durum analizi alt başlıklarından olan kuruluş içi analiz; insan kaynaklarının yetkinlik düzeyi, kurum kültürü, teknoloji ve bilişim altyapısı, fiziki ve mali kaynaklara ilişkin analizlerin yapılarak idarenin mevcut kapasitesinin değerlendirilmesidir. Bu çalışmanın konusunu oluşturan örgüt kültürü analizi de durum analizi süreci kapsamındaki kuruluş içi analizlerdendir.

Sonuç olarak yükseköğretim alanında meydana gelen gelişmeler ve yeni işbirlikleri, stratejik planlamanın üniversiteler için ne derecede önemli olduğunu, dolayısıyla stratejik planlamanın eğitim politikaları yanında çevreye de uyum sağlayarak üniversiteleri daha iyi bir geleceğe götüreceği açıktır (Nayeri vd., 2008:310).

\section{Örgüt Kültürü}

Yönetim ve organizasyon alanyazınında en popüler ve yoğun çalışılan konularından birisi olmasına rağmen, örgüt kültürünün kavram olarak tanımlanması, sınırlarının ve bileşenlerinin belirlenmesi, özellikleri ve fonksiyonları anlamında üzerinde henüz uzlaşı sağlanamamıştır. Kültür kavramının -dinamik doğasından kaynaklı- çok sayıda tanımının yapılması ve pek çok disiplince çeşitli anlamlar yüklenmesi bu durumun sebepleri arasında sayılabilir. Hofstede kültürü bir grup insanı diğerlerinden ayıran aklın ortak programlaması olarak tanımlarken; House vd. bir topluluğun üyelerinin ortak deneyimlerinden doğan ve nesiller boyu aktarılan paylaşılmış değerler, tutumlar, inançlar, yorumlar ve önemli olaylar şeklinde tanımlamışlardır. (Hofstede, 1984: 225; House vd., 2002:3). Zaman içerisinde -entelektüel sermaye- insan kaynağının öneminin anlaşılmasıyla kültür kavramı, 1900'lerin son çeyreğinde yönetim literatürüne girmiştir. Sosyoloji ve antropoloji literatüründe geçen kültür kavramı, Pettigrew'in 1979 yılında "Örgüt kültürleri üzerine inceleme" adlı makalesiyle yönetim alanyazınına giriş yapmış, o tarihten günümüze dek tanımı, boyutları ve yöntemleri araştırmaların ve tartışmaların odağında yer almıştır.

Örgüt kültürü, örgüt çalışanlarına davranış modelleri ve iş yapma şekilleri konusunda rehberlik eden, etkileşimle ortaya çıkan tutum, inanç ve beklentiler modelidir (Armstrong, 1990:206). Camerer ve Vepsalainen'e (1998:115) göre örgüt kültürü, örgüt çalışanlarının beklemedikleri durumlarla karşılaşmaları halinde onlara rehberlik eden kurallar setidir. Örgüt kültürü; bireylerin eylemlerini etkileyen, düşünme yöntemleri, değerler ve normlar dizisidir; bir örgütü bir arada tutan sosyal bir yapıştırıcıdır; işgörenlerce paylaşılan ve örgütü kaynaştıran, değerler, varsayımlar, inançlar, beklentiler, felsefeler, ideolojiler yaklaşımlar ve normlardır; bir örgütün kişiliğini yansıtır, çalışanların memnuniyeti ve örgütün başarısı üzerinde önemli bir etki gücüne sahiptir (Thom, 1990:182; Wooten ve Crane, 2003:275; Szilagyi ve Wallace, 1987: 519; Kane-Urrabazo, 2006;188) şeklinde değişik ve çeşitli tanımları mevcuttur.

Kültürün farklı disiplinler tarafından, farklı tanımlarının yapılmış olmasına karşın; insanları birbirine bağlayıcı özelliğe sahip olması nedeniyle "sosyal yapıştırıcı/harç" gibi ifadeler üzerinde ortak bir uzlaşının hakim olduğu görülmektedir. Diğer taraftan, Newstrom ve Davis (1993: 59), örgüt kültürünün özelliklerini; ayırt edicidir, kararlı bir yapıdadır, ifade edilmeden de anlaşılabilir, semboliktir, bütünleştiricidir, kabul görmüştür, üst yönetimin bir yansımasıdır şeklinde sıralamıştır. Schein'e göre (2002:18) örgüt kültürü, örgütçe belirlenen ortak hedeflere ulaşılması, örgüt üyelerince birlik beraberlik duygusunun oluşturulması, örgüt içi-örgüt dışı gelişmelerden etkilenerek çevresel değişime adapte olmayı sağlaması nedeniyle önemlidir.

Örgütlerin sistem yaklaşımı çerçevesinde değerlendirilmeye başlanmasıyla birlikte; yapı, strateji ve teknolojilerinin başarı sağlamak için yeter kriterler olmadığının farkına varılmıştır. Pfeffer, (1995:5) rekabet avantajı sağlamanın temelinin değiştiğini, geleneksel başarı kaynakları sayılan ürün ve süreç teknolojileri, korumacı piyasalar, ölçek ekonomisi, mali kaynaklara ulaşabilme gibi konuların, eskisi kadar rekabet avantajı sağlamaya yetmediğini; insanların yönetilme pratiğinden türeyen örgüt kültürünün, günümüzde bu faktörlerden daha önemli hale geldiğini belirtmiştir. Cabrera ve Bonache (1999:55) ise, pozitif ve güçlü bir örgüt kültürünün oluşturulmasında stratejik insan kaynakları uygulamalarının önemini vurgulamaktadır. 
Öte yandan, örgüt kültürünün önemli bir özelliği de oluşum şekliyle ilgilidir. Örgüt kültürü ya kurucularca oluşturulur ya da zamanla kendiliğinden oluşur. Örgüt kültürünün zamanla oluşması, işgörenlerin inanç ve değerlerine göre şekillenmesi ile açıklanabilir ve örgütsel bağlllığa katkıda bulunur. Diğer taraftan, her kurucunun oluşturacağı kültürel değerler kendi yetiştirilme tarzının yansımasıdır. Bu anlamda örgüt kültürü; 1. Kurucunun gruba getirdiği varsayımların ve teorilerin, 2. Grubun sonradan kazandığı deneyimlerin ortak çalışmasını yansıtır (Hofstede, 1984:105; Çetin, 2004:120).

O’Reilly'ye (1989:16) göre, güçlü bir örgüt kültürünü değerli kılan iki neden bulunmaktadır. Birinci neden güçlü kültürün, kültür-strateji uyumunu daha kolay sağlıyor olmasıdır. Oluşturulan stratejilerin başarıyla uygulanabilmesi uygun bir kültürel zeminle mümkün olabilmektedir. Bu nedenle örgütsel yapı ve stratejide değişiklik düşünülürken, kültürün temelini oluşturan değerler dikkate alınmalıdır. İkinci neden ise işgörenlerin işletmeye daha fazla bağlanmasını sağlıyor olmasıdır. Sonuç olarak günümüzde örgütlerin varlıklarını sürdürebilmeleri, büyüyüp gelişebilmeleri örgüt-çevre uyumuna bağlıdır ve bu uyumun sağlanmasında en önemli uygulama olan stratejik yönetim sürecine gereken önem verilmelidir diyebiliriz.

\section{Örgüt Kültürü Analizi}

Örgüt kültürü konusunda yapılan çalışmalar incelediğinde örgüt kültürünü kategorize etmeye, tipolojiler oluşturmaya yönelik araştırmalar ile örgütlerin kültürel dokusunu ortaya çıkarmaya dönük araştırmalar şeklinde ayrıldığı görülmektedir. Örgüt kültürü alanyazında ortaya çıkan hakim kanı; kültürün soyut özelliğinin ve değişik açılardan tanımlanmasının ölçme ve değerlendirmeyi zorlaştırdığıdır. Yapılan çalışmalarda örgüt kültürünün farklı özelliklerinin ve boyutlarının ele alınarak incelenmesi; farklı sonuçların elde edilmesine neden olmakta, net bir ortak paydada görüş oluşturmayı zorlaştırmaktadır. (Schein, 1992; Hofstede, 1991; Trompenaars ve Hampden-Turner, 1998; Cameron ve Quinn, 1999). Aslında her bir örgütün insan mozaiği ve diş çevre özellikleri farklı olduğundan, ölçümleme konusunda standart geliştirmek ve kıyaslamalar yapmak çok da rasyonel görünmemektedir.

Koçel (2001:284), konuya durumsallık perspektifinden yaklaşmakta; ancak belirli durumlar ve koşullar (dış çevrenin yapısı, çalışanların nitelikleri ve kullanılan teknoloji vb) çerçevesinde "ideal" in aranması ve böyle bir kültürün özelliklerinin neler olması gerektiğinin tartışılabileceğini ileri sürmüştür. Hayek, (2014:160) ise kültürü tam olarak ölçmenin mümkün olmadığını, ancak ilişkilerini gözlemleyerek izlenimler edinilebileceğinin bazı bilim insanlarınca savunulduğunu belirtmiştir. Smircich (1983) ise, her örgütün kendine özgü bir kültürünün varolmasından dolayı, kantitatif yöntemler yerine kalitatif yöntemler ve standardize olmayan ölçme araçlarının kullanılması gerektiğini vurgulamıştır. Konuyla ilgili bazı araştırmacılar, kültürün sadece kalitatif yöntemlerle, bazıları da kantitatif yöntemler kullanılarak araştırılabileceğini belirtirken, bir grup araştırmacı da her iki yöntemin birlikte kullanılması gerektiğini belirtmektedirler (Hofstede vd., 1990:289; Hon, 2002:64). Örgüt kültürünün ölçülmesinde anket, gözlem, görüşme, grup tartışmaları, doküman analizi, odak grup görüşmeleri gibi yöntemlerin bir veya birkaç tanesi -kültür tasniflerine bağlı olarak- bir arada kullanılabilmektedir. Ölçüm formlarında standart uygulamalar yerine, her örgütün kendi özelliğine göre formülasyonlar geliştirmenin daha doğru olacağı anlaşılmaktadır.

Örgüt kültürü analiz yöntemlerinde olduğu gibi, analizde temel alınacak kültür ögeleri, boyutları, değişkenleri ve sınırları konusunda da tam bir görüş birliği sağlanamadığı görülmektedir. Bazı araştırmacılar inançları, bazıları inanç ve normları, bazıları ise semboller ve/veya örgütsel uygulamaları baz alarak yapılan incelemede örgüt kültürünün açıklanabileceğini ileri sürmektedirler. Örgütsel uygulamalar arasında; güç ve statü sistemleri, ödül-ceza sistemi, kontrol sistemi, performans değerlendirme sistemi, ödeme sistemi, bireysel özerklik, örgütsel yapı, örgütsel destek, örgütsel kimlik, örgütsel adalet, çalışmada hoşgörü ve risk üslenmeyi teşvik vb. örnek olarak sayılabilir. Alanyazın incelendiğinde de örgüt kültürü özelliklerinin farklı kombinasyonlarına ilişkin çok çeşitli örgüt kültürü tipolojilerine rastlanmaktadır. Örgüt kültürü konusunda yapılan çalışmaları sınıflamaya tabi tutarsak, örgüt kültürünü katagorize etmeye, tipolojiler oluşturmaya yönelik araştırmalar ve örgütlerin kültürel dokusunu ortaya çıkarmaya dönük araştırmalar şeklinde ayrıldığını görebiliriz. Şişman'a (2002:41) göre, bir analizde kültürün bütün yönlerini açıklamak oldukça güç olabilir, örgüt kültürü öğelerinden biri yada bir kaçı üzerinde çalışma yapılabilir demektedir. Görüldüğü üzere tanımı, özellikleri, boyutları, analiz yöntemleri farklılı̆̆ı ve çeşitliliği zenginlik oluştursa da karmaşaya da yol açabilmektedir. 
Üniversiteler için Stratejik Planlama Rehberinde (T.C.Strateji ve Bütçe Başkanlığı, 2018:21) belirtildiği üzere; Üniversiteler, stratejik planlarında geleceğe bakışı geliştirirken örgüt kültürünü iyi analiz etmeli ve mevcut örgüt kültürünü dikkate almalıdırlar. Rehberde, örgüt kültürünün analizinden önce, mevcut örgüt kültürünün güçlü ve zayıf yönlerinin tespit edilerek tanımlanması; ardından örgüt kültürünün nasıl olması gerektiği konusunda perspektif oluşturulması, güçlü bir örgüt kültürü oluşturmak için üst yönetimin çalışanlardan, çalışanların da üst yönetimden beklentilerinin öğrenilmesi, sonrasında ise gelecekte olması istenilen ve mevcut örgüt kültürü farkını analizle ortaya koyarak yapılacaklar listesi oluşturup uygulamaya geçilmesi önerilmektedir.

İlgili rehberde örgüt kültürü alt bileşenleri (boyutları) olarak şunlar verilmiştir: Katılım, üst yönetimin katılımcılığı destekleme düzeyi, katılım sağlama mekanizmalarının mevcudiyeti ve çalışanların kararlara katılım düzeyi vb.; işbirliği, bilgi paylaşımı konusundaki mekanizmanın yeterliliği ve etkililiği, takım çalışmasına yatkınlık, koordinasyonda etkililik düzeyi ile yönetimin ve çalışanların işbirliği ve bilgi paylaşımına açıklık düzeyi vb.; bilginin yayılımı, bilginin zamanında ilgili birim ve kişilere iletilme düzeyi ve karar süreçlerinin yeterli bilgiyle desteklenme düzeyi vb.; öğrenme, insan kaynakları yönetiminin gelişmeyi, ilerlemeyi teşvik ediciliği, bilgi, beceri, deneyimlerin paylaşılmasını olanaklı kılan mekanizmaların varlığı; örgüt içi iletişim, iletişimin çalışanlar arasındaki formal düzeyi, katılım ve işbirliğini destekleme düzeyi, üniversitedeki iletişim kanallarının yatay ve dikey olma durumları gibi; değişime açıklık, uygulanan kuralların değişime direnç düzeyi, yeniliğin, yeni fikir ve görüşlerin kabul düzeyi, değişimlerde dış çevre etkilerini dikkate alma düzeyi; paydaşlarla ilişkiler, karar ve uygulamalara paydaşların dahil edilme düzeyi, üniversitenin stratejik planı ile ilgili paydaşların bilgilendirilme düzeyi, paydaş yönetim stratejisinin varlığı, stratejik yönetim, çalışanların stratejik plana yönelik sorumluluk ve farkındalık düzeyi, rutinin dışına çıkılarak stratejik konulara odaklanma düzeyi ve üst yönetimin stratejik plan ve evrelerini sahiplenme düzeyi; bhj ödül ve ceza sistemi, çalışan motivasyonu artırma uygulamalarının varlığı ve etkililik düzeyi, ödül, ceza sisteminin varlığı, uygulanma düzeyi, hatalara karşı üniversitenin yaklaşımı vb. gibi konuların incelenmesi önerilmiştir. Örgüt kültürü analizinin ise anketler, mülakatlar ve arama konferansı gibi yöntemlerle gerçekleştirilebileceği belirtilmektedir. Dolayısıyla araştırma, ilgili rehberdeki örgüt kültürü boyutları ve analiz yöntemleri çerçevesinde ele alınmıştır.

$\mathrm{Bu}$ araştırmada yapı, misyon, girdiler, kaynaklar, paydaşlar ve çevreyle ilişkileri açısından karmaşık örgütler olarak nitelendirilebilen üniversitelerin, stratejik plan gereği yapmak durumunda oldukları örgüt kültürü ölçümlerini, hangi boyutlar ve yöntemlerle yaptıklarını, mevcut stratejik planlarını inceleyerek ortaya koymak amaçlanmıştır.

\section{Yöntem}

\section{Araştırmanın Amacı ve Önemi}

Örgüt kültürü; motivasyon, performans ve verimliliği etkileyen, beşeri sermayeyi şekillendirerek örgütlere farklılık özelliği kazandıran doku olması nedeniyle, stratejik plan yaparak geleceğini şekillendirme çabasında olan her örgütün önem ve öncelik vermesi gereken konuların başında yer almalıdır. Yukarıda da değinildiği üzere, literatürde üniversitelerde stratejik planlama süreci üzerine son yıllarda yapılmış çalışmalara rastlanmakla beraber; durum analizi başlığındaki kuruluş içi analizlerden biri olan örgüt kültürü analizi üzerine herhangi bir çalışma mevcut değildir.

Araştırmayla, devlet üniversitelerinin stratejik planlarında yer alan örgüt kültürü analizlerinin nasıl yapıldıklarını -Üniversiteler için Stratejik Planlama Rehberinde (kapsam, boyut ve yöntem olarak) önerildiği şekliyle yapılıp yapılmadığını- detayları ile ortaya koymak, uygulamaya dikkat çekmek ve bu bağlamda yükseköğretim kurumlarının stratejik planlarında izledikleri politikaların iyileştirilmesine ve bilimsel literatüre katkı sağlamak amaçlanmıştır.

\section{Araştırma Deseni ve Kapsamı}

Araştırmanın çalışma grubunu 128 devlet üniversitesi oluşturmaktadır. Araştırma tarama modelinde desenlenmiş olup, veriler üniversitelerin stratejik planlarında yer alan örgüt kültürü analizlerini -var olduğu şekliyle- betimlemeye çalışmak için doküman inceleme tekniği kullanılmıştır. Doküman incelemesi, hem basılı 
hem de elektronik materyalleri incelemek veya değerlendirmek için sistematik bir işlemdir ve diğer araştırma yöntemlerinde olduğu gibi, anlam çıkarmak, anlayış kazanmak ve ampirik bilgi geliştirmek için verilerin incelenmesini ve yorumlanmasını gerektirir (Bowen, 2009:27). Nisan 2019-Ocak 2020 tarihleri arasında yapılan tarama sonucu; stratejik planları T.C. Cumhurbaşkanlığı Strateji ve Bütçe Başkanlığı'nca onaylanan ve ilgili kuruma bağlı "Kamuda Stratejik Yönetim" adlı web sitesinde paylaşıma açılan stratejik planlar derlenmiştir. $\mathrm{Bu}$ web sitesinde bulunamayan planlar için ise üniversitelerin web sayfaları incelenerek tamamlanmaya çalışılmıştır. Ancak her iki sayfada da bulunamayan ve 2019 sonu itibariyle plan süresi tamamlanan ve yeni dönem planları henüz yayınlanmayan veya yeni kurulmuş ancak stratejik planları henüz yayınlanmamış üniversiteler kapsam dışı bırakılmıştır. Sonuç olarak toplam 104 devlet üniversitesinin stratejik planları çalışma grubu olarak; stratejik planın durum analizi bölümündeki özdeğerlendirmelerden birisi olan kuruluş içi analizlerinden "örgüt kültürü analizi" de çalışma alanı olarak belirlenmiştir. İlgili plan döneminde örgüt kültürü analizlerinin yapılıp yapılmadığı, yapılan analizlerde hangi örgüt kültürü alt boyutlarının değerlendirmeye alındığı ve hangi analiz yöntemlerinin kullanıldığı belirlenmeye çalışılmıştır. Araştırmada elde edilen verileri açılayabilmek için gerekli olan kavram ve ilişkilere ulaşmak amacıyla nitel analiz yöntemlerinden içerik analizi yöntemi kullanılmıştır.

İçerik analizi, sözel-yazılı verilere, sonradan istatistik işlemlerin uygulanabilmesine ve belirli bir kavram, görüş, durum, özellik ya da değişken hakkında önemli bilgiler edinmeye olanak sağlar (Tavşancıl ve Aslan, 2001:21). Cohen vd., 2007:114)'a göre içerik analizi, eldeki yazılı bilgilerin temel içeriklerinin ve içerdikleri mesajların özetlenmesi ve belirtilmesi işlemi olarak da tanımlanmaktadır. Sosyal bilimler alanında sıklıkla kullanılan içerik analizi, belirli kurallara dayalı kodlamalarla kitap, kitap bölümü, mektup, tarihsel dokümanlar, gazete başlıkları ve yazıları gibi bir metnin bazı sözcüklerinin daha küçük içerik kategorileri ile özetlendiği sistematik, yinelenebilir bir teknik olarak tanımlanabilir. Bu çalışma kapsamında içerik analizi yöntemi; verileri sınıflandırmak, kıyaslamak ve buna dayanarak kavramsal sonuçlara varmak amacıyla tercih edilmiştir.

Araştırma kapsamındaki üniversiteler kuruldukları dönem itibariyle üç gruba ayrılarak incelenmiştir.

1.Grup Üniversiteler: 1980 yılı ve öncesi kurulanlar,

2.Grup Üniversiteler: 1981-2000 tarihleri arasında kurulanlar,

3.Grup Üniversiteler: 2001 yılı ve sonrası kurulanlar.

Bu çalışmada içerik analizi yapılırken stratejik planlarda yer alan örgüt kültürü verileri Microsoft Office sistemindeki Excel programına işlenmiş ve ayıklama işlemine tabi tutulmuştur. Ardından veriler örgüt kültürü alt boyutlarına göre kategorize edilerek kodlanmaya çalışılmış ve oluşturulan matrislere işlenmiştir. $\mathrm{Bu}$ amaç doğrultusunda elde edilen verilerden; üniversitelerin örgüt kültürü analizlerini hangi alt boyutları dikkate alarak değerlendirdiği ve hangi yöntemleri kullanarak ölçümledikleri belirlenmeye çalışılacaktır.

Bu amaç doğrultusunda aşağıdaki sorulara yanıt aranmıştır:

1. Üniversitelerin stratejik planlarında, kuruluş içi analiz kapsamında örgüt kültürü analizleri yapılmış midir?

2. Örgüt Kültürü "Üniversiteler için Stratejik Planlama Rehberinde" önerilen (ve/veya farklı) nitel analiz yöntemleriyle ölçümlenmiş midir?

3. Örgüt kültürü analizleri "Üniversiteler için Stratejik Planlama Rehberinde" önerildiği üzere 9 alt bileşen (Katılım, işbirliği, bilginin yayılımı, öğrenme, örgüt içi iletişim, paydaşlarla ilişkiler, değişime açıklık, stratejik yönetim, ödül ve ceza sistemi) kapsamında değerlendirilmiş midir?

\section{Araştırmanın Geçerlik ve Güvenirliği}

Araştırmanın güvenirliği, araştırmada araştırmacı üçgenlemesi ve Miles ve Huberman'ın (1994) geliştirdiği formül uygulanarak sağlanmaya çalışılmıştır. Araştırmacı üçgenlemesi, elde edilen verilerin birden fazla araştırmacı tarafından incelenmesi ve değerlendirilmesi durumudur (Guion, 2002:2). 
Araştırmada elde edilen verilerin örgüt kültürü alt boyutlarına göre kategorize edilmesi, kodlanması ve matrise işlenmesi konuları hem araştırmacı hem de araştırmacı dışında bir öğretim üyesi tarafından ayrı ayrı değerlendirilmiştir. Elde edilen veriler ışığında oluşturulan tema ve alt temalar kapsamında "görüş birliği" ve "görüş ayrılığı" olan konular tartışılmış; gerekli düzenlemeler ve kodlamalar yapılmıştır. Kodlayıcılar arası güvenirlik Miles ve Huberman'ın (1994) uzlaşma yüzdesi kullanılarak hesaplamıştır. Güvenirlik = Görüş Birliği / (Görüş Birliği + Görüş Ayrıllğı). Hesaplama sonucunda araştırmanın güvenirliği, örgüt kültürü analiz yöntemleri ve alt bileşenleri değerlendirmesinin ortalaması alınarak \%93 olarak hesaplanmıştır. Güvenirlik hesaplarının \%70'in üzerinde çıkması, araştırma için güvenilir kabul edilmektedir (Miles ve Huberman, 1994:278-280). Buna göre elde edilen sonuç güvenirliğini ortaya koymaktadır.

\section{Araştırmanın Sinırlılı̆̆}

Araştırma, içinde bulunulan plan döneminde geçerliliği olan stratejik planları içermektedir. İlgili sayfalarda ulaşılamayan devlet üniversiteleri stratejik planlarının, -ve ayrıca vakıf üniversitelerinin stratejik planlarınınaraştırmaya dahil edilememesi çalışmanın kısıtını oluşturmaktadır. Bu nedenle araştırma, incelemeye alınan üniversitelerin örgüt kültürü analizlerinin değerlendirilmesi ile sınırlılık göstermektedir.

\section{Bulgular ve Yorumlar}

Araştırmanın bu bölümünde araştırmaya ilişkin bulguların içerik analizine geçmeden önce incelenen üniversitelerin kuruluş yılları ve stratejik plan dönemleri hakkında bilgi vermek yararlı olacaktır.

Devlet üniversitelerinin kuruluş tarihleri hakkında genel fikir edinmek için sınıflandırma toplam sayı üzerinden yapılmıştır. Çalışma kapsamında ele alınan 128 devlet üniversitesinin 21'i (\%16,4) 1980 yılı ve öncesi, 31'i (\%24,2) 1981-2000 yılları arasında kurulmuş, üniversitelerin sayısının en fazla arttığ dönemin 2001 yılından günümüze kadarki dönem olduğu Tablo 1'de görülmektedir. 2020 yılı itibariyle mevcut devlet üniversitelerinin yaklaşık \%60'ı 2001 yılı ve sonrası kurulmuştur.

Tablo 1. Devlet Üniversitelerinin Kuruluş Dönemleri

\begin{tabular}{lcccc}
\hline $\begin{array}{l}\text { Üniversite Kuruluş } \\
\text { Dönemleri }\end{array}$ & $\begin{array}{c}\text { Araştırma } \\
\text { Kapsamındaki } \\
\text { Üniversiteler }\end{array}$ & $\begin{array}{c}\text { Araştırma Kapsamı } \\
\text { Dişında Kalan } \\
\text { Üniversiteler }\end{array}$ & $\begin{array}{c}\text { Toplam Üniversite } \\
\text { Sayısı }\end{array}$ & $\%$ \\
\hline 1980 ve Öncesi & 20 & 1 & 21 & 16,4 \\
\hline $1981-2000$ & 30 & 1 & 31 & 24,2 \\
\hline 2001 ve Sonrası & 54 & 22 & 76 & 59,4 \\
\hline Toplam & 104 & 24 & 128 & 100.0 \\
\hline
\end{tabular}

Tablo 2'de 2020 yılında aktif planı mevcut üniversitelerin plan dönemleri görülmektedir. 24 (\%18,7) devlet üniversitesinin planlarına T.C.Strateji ve Bütçe Başkanlığı ve bu üniversitelerin resmi web sayfalarından ulaşılamamıştır. Bu durumun nedeni, bazı üniversitelerin (4 üniversite) mevcut stratejik plan dönemlerinin 2019 yılı itibariyle sona ermesi ve yeni dönem planlarının da hazırlıklarının tamamlanmamış veya henüz onaylanmamış olmasıdır. Stratejik planlarına ulaşılamayan diğer üniversiteler ise; 2010 yılında kurulan 1, 2015 yılında kurulan 4, 2016 yılında kurulan 2, 2017 yılında kurulan 1 ve 2018 yılında kurulan 12 üniversite olmak üzere toplam 24 üniversiteden oluşmaktadır. Bu 24 üniversite stratejik planı çalışma kapsamı içine alınamadığından, analiz ve değerlendirmeler 104 devlet üniversitesi planları üzerinden yapılacaktır.

Tablo 2. Üniversitelerin Stratejik Plan Dönemleri

\begin{tabular}{ccc}
\hline $\begin{array}{c}\text { Üniversitelerin } \\
\text { Stratejik Plan Dönemleri }\end{array}$ & $\begin{array}{c}\text { Üniversite } \\
\text { Sayıs (f) }\end{array}$ & $\%$ \\
\hline $2016-2020$ & 7 & 5,5 \\
\hline $2018-2022$ & 31 & 24,2 \\
\hline $2019-2023$ & 29 & 22.6 \\
\hline
\end{tabular}


E. Bahar 12/2 (2020) 2017-2030

\begin{tabular}{ccc}
\hline $2020-2024$ & 23 & 18,0 \\
\hline $2017-2021$ & 14 & 11.0 \\
\hline Plan Yok & 24 & 18,7 \\
\hline TOPLAM & 128 & 100.0 \\
\hline
\end{tabular}

Araştırma kapsamındaki aktif stratejik plana sahip 104 devlet üniversitesinin örgüt kültürü analiz verileri dönemler itibariyle aşağıdaki Tabloda verilmiştir.

Tablo 3. Stratejik Plana Sahip Üniversitelerin Örgüt Kültürü (ÖK) Analizleri

\begin{tabular}{ccccccc}
\hline $\begin{array}{c}\text { Üniversite } \\
\text { Grubu }\end{array}$ & \multicolumn{2}{c}{$\begin{array}{c}\text { ÖK Analizi Yapılan } \\
\text { Üniversiteler }\end{array}$} & \multicolumn{2}{c}{$\begin{array}{c}\text { ÖK Analizi Yapilmayan } \\
\text { Üniversiteler }\end{array}$} & \multicolumn{2}{c}{$\begin{array}{c}\text { Toplam } \\
\text { Unniversiteler }\end{array}$} \\
\cline { 2 - 7 } & Frekans & $\%$ & Frekans & $\%$ & Frekans & $\%$ \\
\hline 1.Grup & 12 & 60,0 & 8 & 40,0 & 20 & 19,2 \\
\hline 2.Grup & 19 & 63,3 & 11 & 36,7 & 30 & 28,8 \\
\hline 3.Grup & 39 & 72,2 & 15 & 27,8 & 54 & 52,0 \\
\hline Toplam & 70 & 67,3 & 34 & 32,7 & 104 & 100 \\
\hline
\end{tabular}

Araştırmaya dâhil edilen -aktif stratejik plana sahip- bütün üniversitelerin kuruluş içi analizleri örgüt kültürü analizleri açısından detaylı bir şekilde incelenmiş ve gruplandırılmıştır. 1.Grupta yer alan 20 üniversiteden 8 üniversite (\%40), 2.Gruptaki 30 üniversiteden 11'i (\%37) ve 3. Gruptaki 54 üniversiteden 15 üniversite (\%28) stratejik planlarında örgüt kültürü analizine ilişkin herhangi bir bilgiye yer vermemişlerdir. İncelenen toplam 104 üniversiteden 70'i (\%67) kuruluş içi analizlerinde örgüt kültürleri hakkında bilgiye/analize yer verdiklerinden, içerik analizi ana kütlesini bu üniversiteler oluşturmaktadır.

Üniversiteler için Stratejik Planlama Rehberinde (2018) örgüt kültürü analizi için önerilen yöntemler; anketler, arama konferansı, mülakatlar vb. yöntemlerdir. Tablo 4.de araştırma kapsamındaki üniversitelerin örgüt kültürü analizi için kullandıkları yöntemler verilmiştir.

Tablo 4'te görüldüğü üzere 1.Grupta bulunan 12 üniversiteden 5'i (\%42), 2.Gruptaki 19 üniversiteden 4'ü (\%21) ve 3.Gruptaki 39 üniversiteden 3'ü (\%8) örgüt kültürü analizlerinde özdeğerlendirme çalışması yapılarak anket uygulanmıştır. Örgüt kültürü değerlendirmesi yapan üniversiteler içinde anket yöntemiyle ölçümleme yapmayı tercih eden üniversitelerin oranı \%17 gibi düşük düzeyde kalmaktadır. (Aktif stratejik plana sahip 104 üniversite açısından değerlendirildiğinde ise bu oran \%11'lere düşmektedir.) Bunlarındışında kalan ve \%83'lük kısmı oluşturan 58 üniversitenin örgüt kültürleri ise, stratejik plan hazırlayan yöneticilerce subjektif şekilde değerlendirilmeler yapılarak ifade edilmeye çalışılmıştır. Anket yöntemi ile yapılan ölçümlemelerin; sayıca az olmaları ve uygulama farklılıklarını görebilmek adına tek tek incelenerek detaylandırılması yararlı olacaktır.

Tablo 4. Stratejik Plana Sahip Üniversitelerin Örgüt Kültürü Analiz Yöntemleri

\begin{tabular}{cccc}
\hline Üniversite & & \multicolumn{2}{c}{ Örgüt Kültürü Analiz Yöntemleri } \\
\cline { 3 - 4 } Grubu & Frekans (f) & Anket (f) & Yönetici Değerlendirmesi (f) \\
\hline 1.Grup & 12 & 5 & 7 \\
\hline 2.Grup & 19 & 4 & 15 \\
\hline 3.Grup & 39 & 3 & 36 \\
\hline Toplam & 70 & 12 & 58 \\
\hline
\end{tabular}

1.Grup üniversiteler; bir üniversite incelemesini yedi alt boyut üzerinden (örgüt içi iletişim, bilgi paylaşımı ve erişimi, katılımcılık düzeyi, iş yapma kültürü, değişime açıklık, hiyerarşik yapı, liderlik ve yetki devri yapısı) gerçekleştirmiş, sonuçları tablo ve grafikle destekleyerek, güçlü, zayıf yönler ile yapılması gerekenler tablolaştırılarak anlatılmıştır. 1.Gruptaki ikinci üniversitede, Stratejik Plan Rehberinde belirtilen örgüt kültürü alt bileşenleri çerçevesinde; mevcut durum ve beklenen durum için ayrı ayrı ölçüm yapılmış, sonuçlar rakamsal olarak değil, her bir alt bileşen için düşük, orta, ortalama üstü şeklinde ifadelendirilmiştir. Üçüncü üniversite aynı şekilde rehberdeki dokuz alt bileşen üzerinden ölçümleme yaparak tablo ve grafikle ortalamalar sunulmuştur. Dördüncü üniversitede dokuz alt bileşene ait ifadelerden ön plana çıkanlar sözel 
belirtilerek örgüt kültürünün güçlü olduğu ve içselleştirildiği yorumu yapılmıştır. Bu gruptaki son üniversite ise ölçümlemesini Cameron ve Quinn'in geliştirdiği örgüt kültürü tipolojisini kullandıkları görülmektedir. "Hiyerarşi", "klan", "adhokrasi" ve "pazar" kültüründen hangisinin üniversitelerinde daha egemen olduğu analiz edilmiş ve örgüt kültürü tipi olarak hiyerarşi kültürünün öne çıktığı belirtilmiştir. Ayrıca, elde edilen verilerden yola çıkarak rehberdeki dokuz alt bileşene ilişkin özdeğerlendirme yapılmıştır.

2.Grupta anket yoluyla yapılan örgüt kültürü değerlendirmeleri ise; iki üniversite iç paydaş anketlerinde bulunan örgüt kültürü alt bileşenlerine yönelik ifadelerin ortalamalarını sunarak durum değerlendirmeleri yapmışlardır. Bir üniversite ise, yapmış olduğu anket uygulamasının değerlendirmesini, her bir alt bileşen için sonuçları olumlu-olumsuz şeklinde yüzde oranlarla ifade etmişlerdir. Bu gruptaki son üniversite de çalışanların "hiyerarşi", "klan", "adhokrasi" ve "pazar" kültürü açısından algılarını ölçümlemiş, her bir boyuta ilişkin yüzde oranlar verilmiş, alt bileşenlerle kısmen ilişkilendirilerek açıklanmıştır.

3.Gruptaki üniversitelerden bir tanesinde dokuz alt bileşene ilişkin ifadelerin yer aldığı anket sonuçları, bileşen bazında ayrı ayrı anlatım ve grafikle verilmiştir. Diğer üniversitede, özdeğerlendirme anketlerindeki örgüt kültürüne yönelik ifadelerin ortalamaları grafikle gösterilmiş, güçlü-zayıf yönleri ile çözüm önerilerinin bulunduğu tablo ile desteklenmiştir. Bu gruptaki 3.üniversitede ise, 20 alt boyutlu ölçek kullanarak detaylı ölçüm yapılmış, sonuçların ortalaması grafikle gösterilmiş ve zayıf ve sorunlu alanlar çözüm önerileri içeren tabloyla desteklenerek açıklanmaya çalışılmıştır.

Görüldüğü üzere örgüt kültürü değerlendirmelerinin \%17'sini anket çalışmasıyla ölçümlemeler oluşturmakta, geri kalan \%83'lük bölümde ise herhangi bir veri toplama uygulaması yapılmaksızın genel değerlendirmeler şeklinde yapıldığından, sınıflamada yönetici değerlendirmesi kategorisine işlenmiştir. Bu değerlendirmelerden 21 stratejik planda örgüt kültürü tanımı, önemi ve genel değerlendirme, 6 planda alt bileşenler bazında genel değerlendirme, 6 planda kalite çalışmalarına yer verme, geri kalanlarda ise, mevcut ve planlanan uygulamalara (konuyla ilgili anket çalışmalarının halihazırda yürütüldüğü, yeni üniversite olunması nedeniyle henüz analiz yapılamadığı vb.) yer verilmiştir.

Üniversiteler için Stratejik Planlama Rehberinde değerlendirme boyutları olarak belirtilen/önerilen örgüt kültürü alt bileşenlerinin stratejik planlarda irdelenip irdelenmediği incelenmiş sonuçlar Tablo 5'de gösterilmiştir.

Tablo 5. Alt Bileşenler Açısından Örgüt Kültürü Değerlendirmeleri

\begin{tabular}{|c|c|c|c|c|c|c|c|c|}
\hline \multirow{3}{*}{$\begin{array}{c}\text { Örgüt Kültürü Analizi } \\
\text { Alt Bileşenleri }\end{array}$} & \multicolumn{6}{|c|}{ Üniversite Grupları } & \multirow{2}{*}{$\begin{array}{l}\text { Toplam } \\
(\mathrm{N}=70)\end{array}$} & \multirow[b]{2}{*}{$\%$} \\
\hline & \multicolumn{2}{|c|}{$\begin{array}{l}\text { 1.Grup } \\
(\mathrm{N}=12)\end{array}$} & \multicolumn{2}{|c|}{$\begin{array}{l}\text { 2.Grup } \\
(\mathrm{N}=19)\end{array}$} & \multicolumn{2}{|c|}{$\begin{array}{l}\text { 3.Grup } \\
(\mathrm{N}=39)\end{array}$} & & \\
\hline & $\mathrm{f}$ & $\%$ & $\mathrm{f}$ & $\%$ & $\mathrm{f}$ & $\%$ & $\mathrm{f}$ & $\%$ \\
\hline Katılım & 11 & 91,7 & 14 & 73,7 & 24 & 61,5 & 49 & 70,0 \\
\hline İşbirliği & 8 & 66,7 & 12 & 63,2 & 18 & 46,2 & 38 & 54,3 \\
\hline Bilginin yayılımı & 8 & 66,7 & 12 & 63,2 & 24 & 61,5 & 44 & 62,9 \\
\hline Öğrenme & 6 & 50,0 & 8 & 42,1 & 17 & 43,6 & 31 & 44,3 \\
\hline Örgüt içi iletişim & 9 & 75,0 & 17 & 89,5 & 27 & 69,2 & 53 & 75,7 \\
\hline Paydaşlarla ilişkiler & 6 & 50,0 & 11 & 57,9 & 11 & 28,2 & 28 & 40,0 \\
\hline Değişime açıklık & 8 & 66,7 & 10 & 52,6 & 14 & 35,9 & 32 & 45,7 \\
\hline Stratejik yönetim & 4 & 33,3 & 8 & 42,1 & 13 & 33,3 & 25 & 35,7 \\
\hline Ödül ve ceza sistemi & 5 & 41,7 & 10 & 52,6 & 12 & 30,8 & 27 & 38,6 \\
\hline
\end{tabular}

Örgüt kültürü anket çalışmalarında, çoğunlukla alt bileşenler açısından değerlendirmelerde bulunulduğundan kategorize etmek kolay olmuştur, ancak yapılan genel değerlendirmeleri (\%83'lük kısım) dokuz alt bileşen açısından sınıflandırmak, yorumlamak nispeten daha karmaşık ve zorlayıcı olmuştur. Tablo 5 'te görüldüğ̈̈ üzere örgüt kültürü analizinde en çok değerlendirme yapılan alt bileşenler sırasıyla örgüt içi iletişim $(\% 75,7)$, katılım $(\% 70)$, bilginin yayılması $(\% 62,9)$ şeklindedir. En az değinilen alt bileşenler ise, stratejik yönetim $(\% 35,7)$, ödül ve ceza sistemi $(\% 38,6)$ ve paydaşlarla ilişkiler $(\% 40)$ konuları olmuştur.

\section{Sonuç ve Tartışma}


Günümüz piyasa mekanizması sadece işletmelerin değil, kamuya ait örgüt ve kuruluşların da iş yapma yöntem ve araçlarını değiştirmiştir. Stratejik düşünme ve karar alma, performans, sonuç odaklılık, toplam kalite yönetimi vb. gibi araçların yaygınlaşması, bazı kamu örgütlerini şirketler gibi yönetilmeye zorlamış, stratejik yönetim anlayışı çerçevesinde hareket etmeye yöneltmiştir. Bu değişim yükseköğretim kurumlarına da -eğitim-öğretim ve araştırma yapma klasik görevlerinin yanında- yeni roller ve sorumluluklar yüklemiş, yönetilmeleri daha zor ve karmaşık bir hal almıştır.

Bilgi ve teknolojiyi üretebilen, kullanabilen, değer yaratabilen nitelikli işgücü yetiştirebilen, Ar-Ge faaliyetleri yürüten üniversiteler, teknolojik ve ekonomik gelişmeye ve sosyal sermayeye önemli düzeyde olumlu katkılar sağlamaktadırlar. Birnbaum'a (1988) göre, geçirgen sınırlara sahip olan üniversiteler ve çevreleri arasında çok çeşitli ilişkilerin mevcudiyeti, açık bir sistem olmaları, karmaşık bir yapıya sahip olmalarına neden olmakta; ayrıca, fikirler, kaynaklar, insanlar ve birçok örgüt ve sistemlerle iç içe olmaları nedeniyle kontrol edilmeleri ve net olarak değerlendirilmeleri güç olabilen çok sayıda karmaşık girdiye sahiptirler. Bu özelliklerden dolayı, ülkemizde de sayıları giderek artan üniversitelerin daha rasyonel ve stratejik kararlarla yönetilmeleri zorunlu olmaktadır.

Örgütlere, sürdürülebilirlik, farklılık, üstünlük ve başarı sağlayan faktörler de, fiziksel kaynaklardan çok beşeri kaynaklar olmaya başlamıştır. Diğer taraftan örgütün kişiliği olarak nitelendirilen ve çalışanlar, müşteriler, kısaca tüm paydaşlar üzerinde son derece etkisi olan örgüt kültürü de önem kazanan yönetim konularındandır. Sağladığı birçok fayda yanında örgütün biçimselleşmesini ve pozitif güdülenmesini kolaylaştırdığı için güçlü bir örgüt kültürü; amaç, politika ve strateji formülasyonu ve uygulamalarında yöneticilere kolaylıklar sağlamaktadır. Kavramsal çerçeve kısmında da açıklandığı gibi, tanımı, sınırları, bileşenleri, analiz yöntemleri itibariyle çeşitlilik ve karmaşa içeren örgüt kültürü konusunda; yine karmaşık yapıya sahip üniversitelerin yaklaşım ve uygulamalarının ne olduğunun belirlenmesi düşüncesi bu çalışmanın çıkış noktasını oluşturmuştur. Bunun için üniversitelerin hazırladıkları stratejik planlara başvurulmuştur.

Türkiye'de kamu yönetiminde stratejik planlama, 2003 yılında kabul edilen 5018 sayılı kanun ile düzenlenmiş ve 2006 yılından itibaren kamu idarelerinde uygulanmaya başlamıştır. Bu araştırmayla, devlet üniversitelerinin stratejik planlarında yer alan kuruluş içi analiz bölümündeki örgüt kültürü analizlerini incelemek amaçlanmıştır ve şu sorular cevaplandırılmaya çalışılmıştır. 1. Üniversitelerin stratejik planlarında, kuruluş içi analiz kapsamında örgüt kültürü analizleri yapılmış mıdır? 2. Örgüt kültürü "Üniversiteler için Stratejik Planlama Rehberinde" önerilen (ve/veya farklı) nitel analiz yöntemleriyle ölçümlenmiş midir? 3. Örgüt kültürü analizleri "Üniversiteler için Stratejik Planlama Rehberinde" önerildiği üzere 9 alt bileşen (Katılım, işbirliği, bilginin yayılımı, öğrenme, örgüt içi iletişim, paydaşlarla ilişkiler, değişime açılık, stratejik yönetim, ödül ve ceza sistemi) kapsamında değerlendirilmiş midir?

Araştırma kapsamındaki (aktif stratejik planları mevcut olan) 104 üniversite, kuruluş tarihleri itibariyle 3 döneme ayrılarak incelenmiştir. Hazırlanan stratejik planların durum analizi başlığı altındaki kuruluş içi analiz alt başlığında; örgüt kültürü analizi, insan kaynaklarının yetkinlik düzeyi, teknoloji ve bilişim altyapısı, fiziki ve mali kaynaklara ilişkin analizlerin yapılarak üniversitenin mevcut kapasitesinin değerlendirilmesi amaçlanmaktadır. İncelenen 104 devlet üniversitesinin stratejik planlarında 70 üniversitenin örgüt kültürü analizine ilişkin değerlendirme yapılmış olduğu görülmüş, 34 stratejik planda örgüt kültürüne ilişkin herhangi bir bilgiye rastlanmamıştır. 104 üniversiteden 70'i (\%67) kuruluş içi analizlerinde örgüt kültürleri hakkında bilgiye/analize yer verdiklerinden, içerik analizi ana kütlesini bu üniversiteler oluşturmuştur. Dolayısıyla 1. Araştırma sorusu \%67 düzeyinde evet olarak yanıt bulmuştur.

Üniversiteler için Stratejik Planlama Rehberinde (2018) örgüt kültürü analizi için önerilen yöntemler; anketler, arama konferansı, mülakatlar vb. yöntemlerdir. Örgüt kültürü değerlendirmesi yapan üniversiteler içinde anket yöntemiyle ölçümleme yapmayı tercih eden üniversitelerin oranı \%17 gibi düşük düzeyde kalmaktadır. (Aktif stratejik plana sahip 104 üniversite açısından değerlendirildiğinde ise bu oran \%11'lere düşmektedir.) Bunların dışında kalan ve \%83'lük kısmı oluşturan 58 üniversitenin örgüt kültürü değerlendirmelerini, tanım, önem, mevcut kısmi uygulamalar ve/veya yapılması planlanan birtakım uygulamalar oluşturmaktadır. Herhangi bir ölçüm çalışması yapılmadan, stratejik plan hazırlayan yöneticilerce subjektif şekilde değerlendirilmeler yapılarak ifade edilmeye çalışılan bu bilgiler, "yönetici değerlendirmesi" başlı̆̆ıyla değerlendirilmek durumunda kalınmış, anlatımlar tasnif ve sınıflandırmaya tabi tutulmuştur. 2. Araştırma 
sorusu da \%11-17 düzeyinde evet olarak cevaplanmıştır. En önemli görev ve misyonlarından biri olan “araştırma" yı yapmadan, kısaca anlatımla örgüt kültürü önemini vurgulayan üniversitelerin sayıca çokluğu dikkat çekmektedir.

“Üniversiteler için Stratejik Planlama Rehberinde” örgüt kültürü değerlendirme boyutları olarak; katılım, işbirliğ̣i, bilginin yayılımı, öğrenme, örgüt içi iletişim, paydaşlarla ilişkiler, değişime açıklık, stratejik yönetim, ödül ve ceza sistemi içeriğinde değerlendirilme yapılması önerilmektedir. Anket çalışmalarında, çoğunlukla alt bileşenler açısından değerlendirmelerde bulunulmuştur, ancak \%83 gibi yüksek bir oran oluşturan kısım genel değerlendirme yaptığından, içerik analizi çalışması alt bileşenleri tespit için bu bölümlerde yoğunlaşmıştır. Yapılan yönetici değerlendirmelerinde en fazla kuruluş içi iletişim (\%75,7), ve katılım (\%70) konusuna değinilmiş, en az değinilen kültür alt bileşenleri ise stratejik yönetim $(\% 35,7)$ ve ödül ve ceza sistemi $(\% 38,6)$ olmuştur. 3. Araştırma sorusunun cevabı olarak 9 alt bileşen değerlerinin ağırlıklı ortalaması alınarak yaklaşık \%52 oranında evet sonucuna ulaşılmıştır.

Araştırma bulgularına göre sonuç olarak; üniversitelerin stratejik planlarında, örgüt kültürü analizlerinin amacına uygun yapılma oranının çok düşük düzeyde kaldığı, aktif plana sahip üniversitelerin \%33'ünün örgüt kültürüne dair hiçbir bilgiye yer vermediği, geri kalan kısmın ise \%17 düzeyinde anket çalışmasıyla ölçüm yaptığı, yapılan anket çalışmalarının bir kısmının memnuniyet veya paydaş anketleri içerisine yerleştirilen kültür sorularıla -böylesine geniş kapsamlı ve kurumun röntgeni olabilecek bir konudeğerlendirmeye tabi tutulduğu tespit edilmiştir. Anket çalışması yapan 12 üniversiteden 2'si de örgüt kültürü tipolojisini belirlemeye yönelik çalışma yapmışlardır.

Oysa, stratejik plan hazırlanırken, hedeflerin gerçekçi olmasının yanında ölçülebilir olması da önemlidir. Ölçümlenmeyen göstergeler, karşılaştırmalı analiz yapmaya fırsat veremeyeceğinden, hazırlanan planların örgütler üzerindeki etkisini izlemek de mümkün olamayacaktır. Örgüt kültürü, çalışma ortamını biçimselleştirmekte, çalışanların iş yapma biçimlerini, performanslarını, motivasyonlarını direkt olarak etkilemektedir. $\mathrm{Bu}$ nedenle örgütsel kültürün önemi fark edilmeli, hangi boyutlarının güçlü, hangi boyutlarının zayıf olduğu belirlenmeli zayıf yönler güçlendirilmeli, güçlü yönler korunmalıdır.

Sonuç olarak, üniversitelerin ideal stratejik planlar oluşturup uygulamalarını sağlayacak stratejik yönetim bilincinin henüz tam olarak yerleşmemiş olduğunu söyleyebiliriz. Bunun nedenleri arasında stratejik planların bir zorunluluk ve prosedür olarak görülmesi, stratejik planlamanın gereği gibi uygulanması sonucu elde edilecek kazanımlar konusunda yeterli bilgiye sahip olunmaması, gerçekçi bir yaklaşım ve özenle uygulanmaması sayılabilir. Örgütlerin varlıklarını devam ettirebilmeleri, rekabet karşısında üstünlük sağlayabilmeleri, çevreyle uyum içinde hareket edebilmeleri; bilgiyi doğru yönetmeleri ve isabetli stratejiler formüle edip uygulamalarıyla doğru orantılıdır. Bu anlamda ülkemizdeki devlet üniversitelerinin yaklaşık \%60'ının 2000'li yıllarda kurulmuş genç üniversite olduğu düşünüldügünde, örgüt kültürü oluşturma ve stratejik planlama uygulamalarının içselleştirilmesinin zaman alacağı da kabul edilmelidir. Bu nedenle, daha sonraki stratejik plan dönemlerinde konuyla ilgili boylamsal çalışmalar yapılması önemli görülmektedir.

\section{Kaynakça}

Albrechts, L. (2001). Inpursuit of new approaches to strategicsatialplanning: a european perspective, International Planning Studies, 6:3, 293-310.

Armstrong, M. (1990). Management Processes And Functions. London, Institute Of Personnel Development.

Bevir, M., Rhodes R.A.W. ve Weller, P. (2003). Traditions of governance: interpreting the changing role of the public sector, Public Administration Review, 81 (1), 1-17.

Birinci, M. (2014). Üniversitelerde stratejik yönetim uygulamalarının performansa etkileri: devlet ve vakıf üniversitelerinin karşılaştırmalı analizi, Yükseköğretim Dergisi, Cilt:4, Sayı:3., 135-147.

Birnbaum, R. (1988). How Colleges Work: The Cybernetics of Academic Organization and Leadership, San Francisco, The Jossey-Bass Publishers.

Blair, R. (2004). Public participation and community development: The role of strategicplanning, Public Administration Quarterly, Spring, 102-147. 
E. Bahar 12/2 (2020) 2017-2030

Bowen, G. A. (2009). Document analysis as a qualitative research method, Qualitative Research Journal, 9(2), 2740.

Bryson, J. M. (2012). Strategic Planning For Public And Nonprpfit Organizations A Guide To Strengthening And Sustaining Organizational Achievement, Fifth Edition, San Francisco, Jossey-Bass.

Bryson, J.(1988). Strategic planning. Big wins and small wins, Public Money And Management, Autumn, 11-15.

Büyük, K. ve Barca, M. (2011). Kamu örgütlerinde stratejik performans yönetim aracı olarak başarı karnesinin kullanımı, Dumlupinar Üniversitesi Sosyal Bilimler Dergisi, 163-174

Cabrera, E.F. ve Bonache, J. (1999). An expert HR system for aligning organizational culture and strategy, Human Resource Planning, 22(1): 51-60.

Camerer, C. F. ve Vepsalainen, A. (1988). The Economic efficiency of corporate culture, Strategic Management Journal, 9, 115-126.

Cameron, K. S. ve Quinn, R. E. (1999).Diagnosting and Changing Organizational Culture, Reading: AddisonWestley.

Cohen, L., Manion, L. ve Morrison, K. (2007). Research Methods In Education, Sixth Edition, New York, Routledge.

Collins, J.C., \& J.I. Porras (1996). Building your company's vision, Harvard Business Review (September/October), 65-77.

Çetin, M.Ö. (2004). Örgüt Kültürü ve Örgütsel Bağlllık. Ankara, Nobel Yayın Dağıtım.

Danışman, A. ve Özgen, H. (2003). Örgüt kültürü çalışmalarında yöntem tartışması: Niteliksel - niceliksel yöntem ikileminde niceliksel ölçümler ve bir ölçek önerisi, Yönetim Araştırmaları Dergisi, 3(2), 91-124.

Guion, L. A. (2002). Triangulation: Establishing TheValidity Of Qualitative Studies. University Of Florida. (ErişimTarihi: 12.01.2020), Https://Sites.Duke.Edu/ Niou/Files/2014/07/W13-Guion-2002Triangulation-Establishing-The-Validity-Of-Qualitative-Research.Pdf

Hayek, F. A. (2014). The Road To Serfdom: Text And Documents, The Definitive Edition (Vol. 2). Routledge.

Hofstede, G. (1984). Culture's Consequences: International Differences In Work Related Values, Sage Publications, Newburg Park.

Hofstede, G. (1991).Cultures and Organizations, London, McGraw-HillCompany.

Hofstede, G., Neuijen, B., Ohayv, D. D. \&Sanders, G. (1990). Measuring organizational cultures: A qualitative and quantitative study across twenty cases,Administrative Science Quarterly, (35), 286-316.

Hon, C.M. (2002). A Quantitative Analysis Of Organizational Culture Perception İn A Same Industry Merger. Ph.D. Thesis, Capella University.

House, R. J., Javidan, M., Hanges, P. ve Dorfman, P. (2002). Understanding cultures and implicit leadership theories across the globe: An introduction to project GLOBE, Journal Of World Business, 37, .3-10.

Kane-Urrabazo, C. (2006). Management's role in shaping organizational culture, Journal Of Nursing Management.14, 188-194.

Koçel, T. (2001). İşletme Yöneticiliği, İstanbul, Beta Yayınları.

Miles, M. B. ve Huberman, A. M. (1994). Qualitative Data Analysis: An Expanded Source book. (2nd Ed). Thousand Oaks, CA: Sage.

Nayeri, M. D., Mashhadi M. M., AndMohajeri, K. (2008). Universities strategic evaluation using balanceds corecard, International Scholarly And Scientific ResearchEInnovation, 2(1), 308-313.

Newstrom. J.W. and Davis.K. (1993). Organizational Behavior At Work. 9.Edition, New York, Mcgraw-HillInc.

O'Reilly, C. (1989). Corporations, culture, andcommitment: motivation and social control in organizations, california Management Review, 31(4): 9-25. 
E. Bahar 12/2 (2020) 2017-2030

Özmen, İ., Özmen, F. ve Sakarya, Ş. (2013). Beş yılda ne değişti?: Üniversitelerde stratejik planlama çalışmaları (Misyon ve vizyon ekseninde karşılaştırmalı bir analiz), Bilgi Ekonomisi Ve Yönetimi Dergisi, C: 8, S: 2, ss. 27-39.

Pettigrew, A. M. (1979). On studying organizational cultures, Administrative Science Quarterly, 24(4), 570-581.

Pfeffer, J. (1995). Rekabette Üstünlüğ̈̈n Sırrı: İnsan, Sinem Gül (Çev), İstanbul, Sabah Gençlik Yayınları A.Ş.

Poister, T., H, Streib, G. (2005). Elements of strategic planning and management in municipal government: status after two decades, Public Administration Review, Vol. 65, No.1, 45-56.

Schein, E. H. (1992). Organizational Culture and Leadership, 2nd Edition, San Francisco, Jossey-Bass.

Schein, E.H. (2002). Örgütsel kültür, Çev: Akbaba, A. Dokuz Eylül Üniversitesi Sosyal Bilimler Enstitüsü Dergisi,4(3), (Orijinal Makalenin Yayım Tarihi 1990), 1-32.

Smircich, L. (1983). Conceptsof cultureandorganizationalanalysis,AdministrativeScienceQuarterly, 339-358.

Szılagyı, A. D. ve M. J. Wallace (1987). Organizational Behavior And Performance. USA, Scott Foresman And Co.

Şişman, M. (2002). Örgütler ve Kültürler, Ankara, Pegem Yayıncılık.

T.C.Cumhurbaşkanlığı, Strateji Ve Bütçe Başkanlığı. (2018). Üniversiteler İçin Stratejik PlanlamaRehberi. Http://Www.Sp.Gov.Tr/Upload/Xspkutuphane/Files/Wtnii+Universiteler Icin Stratejik Planlama R ehberi.Pdf (Erişim Tarihi: 04.04.2019)

T.C.Resmî Gazete, 24.12.2003, Sayı: 25326, Md: 9.

Tavşancıl, E., Aslan, E. (2001). İ̧cerik Analiz ve Uygulama Örnekleri. İstanbul, Epsilon.

Thom, N.(1990). Innovation management in small and medium-sized firms. Management International Review,30-182.

Toma, J. D. (2010). Building Organizational Capacity: Strategic Management In Higher Education, Baltimore, MD: The Johns Hopkins UniversityPress.

Trompenears, F. ve Hampden-Turner, C. (1998). Riding the Waves of Culture: Understanding Cultural Diversity in Global Business, New York, McGraw-Hill.

Wooten, L.P. ve Crane, P. (2003). Nurses as implementers of organizational culture, Nursing Economics, 21(6): 275-279.

Yılmaz, H. ve Kesik, A. (2010). Yükseköğretimde yönetsel yapı ve mali konular: Türkiye'de yüksek öğretimde yönetsel etkinliği artırmaya yönelik bir model önerisi, Maliye Dergisi, 124-163.

Yükselen, C. (1998). Pazarlama-ilkeler-Yönetim, Ankara, Detay Yayınclık. 